\title{
Cyber Portfolio: The Innovative Menu for 21st Century Technology
}

\author{
Ava Clare Marie O. Robles \\ Mindanao State University, General Santos, Philippines
}

\begin{abstract}
Cyber portfolio is a valuable innovative menu for teachers who seek out strategies or methods to integrate technology into their lessons. This paper presents a straightforward preparation on how to innovate a menu that addresses the 21st century skills blended with higher order thinking skills, multiple intelligence, technology and multimedia. Specifically, this cyber portfolio is an administrative tool that manages, organizes, displays and evaluates the e-portfolio of students. Additionally, through cyber portfolio, these e-portfolios or the digitized collection of students' outputs (e.g., text-based, word-processed documents, graphics, videos or multimedia elements, and other e-resources) are easily archived on a Website or other electronic media, such as a CD-ROM (compact disc read only memory) or DVD (digital video disc). With cyber portfolio, teachers can control and easily navigate to the various works of their students as well as track student's e-portfolio. In short, the cyber portfolio provides teachers with a menu or a set of choices that increase their capabilities in using the latest technology while improving their students' abilities to communicate the value of their work. Moreover, this paper, discusses the "hows" of developing a cyber portfolio as an innovative menu that speeds up the teaching-learning process and blends classroom activities with latest technology available in the Internet. Finally, some conclusions on the effective utilization of cyber portfolio as a public table in showcasing students' individual achievements are also presented.
\end{abstract}

Keywords: cyber portfolio, e-portfolio, innovative menu

\section{Introduction}

Technology may often be considered a time idler for students, but it is also a necessity to both teachers and students in making the classroom a connected educational place. As teachers and students get interconnected via global networks, there are an increasing number of universities here and abroad which are in the progression of the utilization of e-portfolio as one of the means of student learning and assessment. In fact, the UG (University of Georgia) made extensive use of e-portfolios in the international technology masters program. Students from that university were encouraged to present publicly a comprehensive e-portfolio of their design work as the culminating assessment in their programme (Department of Instructional Technology, 1999). Apparently, the use of e-portfolio is expanding. Consequently, there is a decrease in the number of paper-pencil examinations. Soon, e-portfolio could be an important requirement for students, because of its impending force in advancing MI (multiple intelligences), HOTS (higher order thinking skills) and integration of technology.

Recognizing the transition from paper-based assessment to the employment of e-portfolio as means to integrate MI, HOTS and technology, it is vital for teachers to learn how to design their cyber portfolio, scaling

Ava Clare Marie O. Robles, Ph.D., professor, College of Education, Mindanao State University. 
beyond traditional boundaries and executing seamlessly across these networks. Hence, teachers ought to have a solid foundation on how to successfully integrate technology into teaching. This know-how is now considered the highlight in the sphere of 21st century learning.

\section{E-portfolio}

Students' exposure to modern technology can be well-utilized by teachers through the making of e-portfolio. The e-portfolio allows learners to articulate their work and take ownership over their own abilities to plan, assess and reflect upon their learning during a specific period of time. Specifically, the e-portfolio is employed to store information, present personal proficiency matrix and proof of growth, accomplishment and reflection. It contains artifacts as proof of learning performance which can be in the form of word, power point files or links to other Web sources.

Teachers usually require e-portfolios to develop students' technology skills or acquaint them with the better use of technology by being used as an aide to their subjects. Moreover, this e-portfolio is a primary tool to provide students with educational experiences that go beyond the four corners of the classroom. Accordingly, many studies show the numerous functions of e-portfolio. Some of them are presented in Table 1.

Table 1

Different Functions of E-portfolio

\begin{tabular}{|l|l|}
\hline Sources & Functions of e-portfolio \\
\hline Wilson et al.(2009) & Plan, record, review, complete record of work and demonstrate skills \\
\hline Luchoomun, McLuckie, and Wesel (2010) & $\begin{array}{l}\text { Sharing evidence, planning, monitoring; review of evidence and review of } \\
\text { literature }\end{array}$ \\
\hline $\begin{array}{l}\text { Individual Research } \\
\text { (Barrett, 2000) }\end{array}$ & Presentation, collection, selection, reflection and direction \\
\hline Gray (2008) & $\begin{array}{l}\text { Serves for lifelong learning that reflects on personal strengths and weaknesses, as } \\
\text { well as recognizing gaps in existing knowledge and competences }\end{array}$ \\
\hline
\end{tabular}

Additionally, the e-portfolio may be in the form of students' activities that permits students to reflect. This reflection activity is geared towards the achievement of the learning objectives.

The increased use of e-portfolio creates the need to design a management tool to track students' e-portfolio with accuracy. The selected teachers of MSU (Mindanao State University) recognizes the need to develop a cyber portfolio (see Figure 1), which is defined as an administrative tool that manages, organizes, displays and evaluates the e-portfolios of students. This can be a dashboard, or a blog of a class Website for linking students' e-portfolios. This facilitates the implementation of flexible, inter-operable and scalable workflow system available on the Web. Its advantage is that it helps teachers monitor their teaching-learning processes as it provides improved output and tracking of processes for better utilization of teaching-learning resources.

As an administrative tool, cyber portfolio enables the teacher to arrange and organize a menu for students' e-portfolios and showcase students' learning achievements. In creating a cybe portfolio, teachers can upload files, pictures, videos and links to other Websites. Additionally, cyber portfolio can be shared with others and published to the Web for efficiency purposes. Students must have an account in the teachers' cyber portfolio that has been customized to meet the requirements of the student's e-portfolio. With the formulation of cyber portfolio, students and teachers are with cutting-edge technology leading to an effective teaching-learning process. This was used by selected teachers to assess students' learning in the College of Education.

Cyber portfolio enables teachers to efficiently design a learning environment, where teachers and students 
collaborate. Eventually, this will result in an effective delivery of learning blended with HOTS, MI and technology. To support this kind of learning mode, educators are encouraged to design their cyber portfolios that include original content, link documents to download and share with other teachers and students. The cyber portfolio, therefore, will not only meet the needs of educators, but also provide authentic evidence of students' learning outcomes and performances.

With cyber portfolio, teachers can easily determine whether their students are going into the core of the courses, because the menu found in the teacher's cyber portfolio ensures these basic skills which are then applied to higher levels of learning. Moreover, the displayed menus will serve as a natural motivator for the students, because they are able to navigate through different resources which are linked in the menu. The menu items that appear in the teacher's cyber portfolio are hyperlinked to open in separate pages or Websites.

However, to operationalize the use of e-portfolios, specific guidance is issued to students of what is expected. In addition, the teacher has the option and opportunity to personalize it. Figure 1 is a sample of teacher's cyber portfolio.

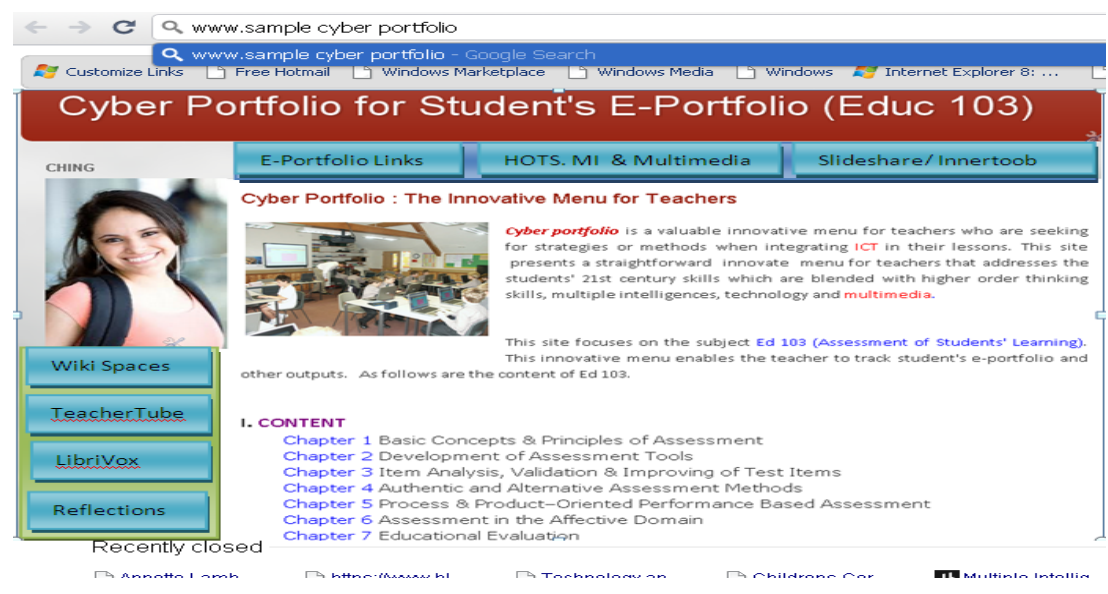

Figure 1. Sample of teacher's cyber portfolio.

Using a qualitative research design, this paper explored how cyber portfolio and e-portfolio meet the required 21st century skills to ensure that students are gaining the maximum benefits of the use of e-portfolios in their study. For better understanding, a conceptual framework is constructed in Figure 2.

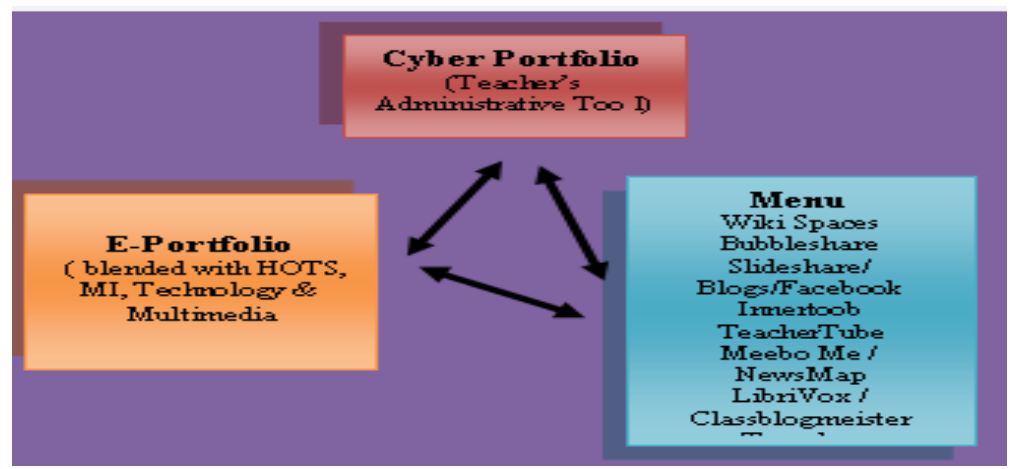

Figure 2. Conceptual framework.

Furthermore, it must be understood that it is the teacher's responsibility to "link" cyber portfolio into students' e-portfolios. The linked e-portfolios then help teachers in tracking or monitoring students' work, as it 
provides first hand evidence of progression and coherence towards course completion. This proof is reflective in nature, which may contain hypermedia links to students' e-files.

Completed outputs from the students are structured and linked to specify that they have sought guidance from the teacher on how the content and structure of their e-portfolios are formulated. None of them, either during their first degree or subsequent modes of service, experience personal development planning or e-portfolio construction. While students are in the process of completing their portfolios, they link it with their peer learning group for evaluation and comments. This encourages social networking, a process that is repetitive in nature and provides feedback about learning.

As the course ends, the e-portfolio evolves from a formative assessment instrument to one that is summative in nature. At this period, students share their e-portfolios with the other groups who then cross-reference the e-portfolio with the course objectives ensuring that students show evidence in the attainment of targets. It may also be used to determine the academic quality of the course, as defined in the assessment criteria of the course syllabus.

Three weeks before the end of the first module, a sample of 25 education students were issued an online assessment survey to complete. The objective of the assessment survey was to determine which procedures they were comfortable with and which would necessitate extra support.

Eighteen out of 25 students responded to the assessment survey. Seven non-responsive students stated time as the factor for non-completion. Responsive students mentioned that it was their first time to use e-portfolios for collecting artifacts. This is justified because students have been undertaking a transition from the traditional mode of course delivery to a blended learning strategy. Ten out of 18 students found the teachers' cyber portfolio as a manageable tool, for instance, they are able to navigate with its links and add artifacts to their e-portfolios and they were excited with their e-portfolios. For example, a student commented: "I researched for concepts and illustrations and was able to place some of these important documents into my e-portfolio. I'm excited as always to explore more..."

Nonetheless, corrective support has been integrated into the lessons at the beginning stage for those who are finding it complex and hard. This is quite challenging, after this prologue, selected students are working in a distance learning mode.

Furthermore, most of the students have reported that they appreciate the variety of links found in the teacher's cyber portfolio to support the content of their e-portfolios. This indicates that they are able to navigate to a variety of activities enriched with MI, HOTS and technology/multimedia. This further implies that students are able to gain sufficient information which is pre-requisites to the development of their e-portfolio. This process of linking artifacts into students' e-portfolios is inspiring, and that, students can demonstrate proficiency before going further to the final stage in using the e-portfolio as evidence of having achieved the course objective. However, it must be noted that the significance of HOTS, MI and technology integration as strategy to learning will have to be highlighted at the introductory stage of the course by the teachers. In particular, teachers have to be proactive in cheering students at this early phase.

\section{Results and Analysis}

Instead of simply summarizing the use of cyber portfolio, e-portfolios as well as how teachers perceive the whole process, the authors may state conclusions by examining this form of innovation.

The findings of this paper indicated that the creation of cyber portfolio as teachers' administrative tool in 
helping students' e-portfolios is feasible in the College of Education. However, the implementation of cyber portfolio and e-portfolios suggests that such usage would oblige the college culture change on students, teachers and staff. The transition from the conventional to the outcome-based assessment model must be initiated with prudence. It may be possible to implement this innovative strategy on graduate courses, over a relatively short timescale, but for a conventional four-year course, it will be more challenging. If such course is modularized and each module is assessed independently, then employing an outcome-based assessment module would need to be considered on an individual module basis. The teacher implications are also considered. Not only will the teachers have to accept the task of designing a cyber portfolio, but they will also have to spend extra time tailoring their existing courses. Indeed, the realization of cyber portfolio for students' e-portfolios will necessitate an extensive course re-alignment.

The emerging cyber portfolio available either as sub-system or modified tool in their own possession, provides scope for significant optimism. For students, this cyber portfolio is needed to guide them in the completion of their e-portfolio. In the case of Newcastle University, Cottrell (2003), a home-grown e-portfolio was developed and successfully applied with nursing, medicine and professional education students (Wijnand, 2004). Even so, the use of cyber portfolio in integrating MI and HOTS to students' e-portfolios creates certain issues, such as time factor.

In MSU of General Santos, the chosen alternative learning mode is to adopt cyber portfolio for students' e-portfolios. Although this is an integrated resolution, with the first application of cyber portfolio for students' e-portfolios, it has encountered challenges and finally overcome certain technological issues, such as downloading e-portfolios to CDs (compact discs). Nevertheless, there is a big potential for execution of cyber portfolio in an online format. It is believed that as technology progresses, cyber portfolio would become healthier, as it has been the case in MSU.

The choice of online implementation of cyber portfolio and e-portfolios requires certain technological proficiency of both teachers and students. With this innovation, it is proposed that teachers must learn how to effectively design their cyber portfolio, while students must develop HOTS in the processes of collection, selection and evaluation for their e-portfolios. Other than that, it is also suggested that teachers develop their own assessment skills and styles, where the responsibility may be on the quality of e-portfolios, guaranteeing 21st century skills blended with HOTS, MI, technology and multimedia rather than grading of conventional students' assignments.

The results from this study also showed that the majority of students have managed to complete their e-portfolios to a satisfactory level, even though they are at the premature phase of using e-portfolios. Furthermore, the results of the study showed that the construction of cyber portfolio for e-portfolios is achievable and can promote quality assessment. Later, it was found out that it can speed up the teaching-learning process, if and only if both students and teachers are convinced about the effectiveness of cyber portfolio and e-portfolio. Finally, teachers must become skilled in preparing their cyber portfolio. With this, the author suggests a change in teaching modes as well as encourages further research in this type of innovation. The following is the innovative menu that addresses the 21st century skills coated with the latest technology or multimedia available in the Internet.

\section{Innovating Menu Blended With HOTS}

When preparing a menu for students' e-portfolios, it is necessary that these key questions are answered to 
verify the level and extent to which higher order skills are integrated: (1) Are students encouraged to externalize ideas or knowledge in their own ways?; (2) Does the activity found in the menu pose questions that are focused on higher order thinking skills?; and (3) Does the Web tool in use support the activity at a higher order thinking skills level?

In analysis level, menus are prepared to provide access to sources which can be used for comparison of content or evidence with sources which are Web-based. With this, students need to be given clear instructions in creating their e-portfolios which are Web-based data. When trying to find responses to analytical questions, students' e-portfolios will serve as an effective technique to support students' analytical understanding.

In synthesis level, teachers must efficiently arrange menus and link it with search engines or sites that appropriately undertake activities involving synthesis. At this stage, students' e-portfolios should involve activities in which they can select pertinent material from within sources, putting source evidence into order and prioritizing it according to selected criteria. Using Web-based frameworks for synthesis (such as mind mapping techniques to link ideas from students' e-portfolios) can be priceless methods to investigate techniques involved in synthesis.

In evaluation level, cyber portfolio is utilized by letting others see the outcomes of their work via email/face book/blogs. Commenting on one another's works enables students to gain evaluative feedback; and contacting experts and specialists via email/face book/blogs to gain ideas and feedback on specific aspects when evaluation can also be a useful technique. Work which is modified as a result of evaluative feedback and Web tools aids this process.

Nevertheless, it must be emphasized that the focus of making the menu is not on technology per se, but rather on how technology is used to promote higher order thinking by using it on tasks that require skills such as problem-solving, reflection and cooperation. The suggested menus that incorporate technologies to promote higher order thinking are shown in Table 2.

Table 2

Suggested Menus for HOTS

\begin{tabular}{|c|c|c|}
\hline HOTS & Sample learning activity & Menu \\
\hline Analysis & $\begin{array}{l}\text { 1. Design a questionnaire to gather information about cyber sex. } \\
\text { 2. Conduct an investigation to produce information to support a view on } \\
\text { "Corruption". }\end{array}$ & $\begin{array}{l}\text { Blog post question on concepts, Wiki, } \\
\text { Innertoob } \\
\text { Classblogmeister }\end{array}$ \\
\hline Synthesis & $\begin{array}{l}\text { 1. Invent a machine to do a specific task. } \\
\text { 2. Design a building to house your study. } \\
\text { 3. Create a new product. Give it a name and plan a marketing campaign. } \\
\text { 4. Write about your feelings in relation to Hell is Real. } \\
\text { 5. Write a TV (television) show, play, puppet show, role-play, song or } \\
\text { pantomime about addiction. }\end{array}$ & $\begin{array}{l}\text { Microblogging } \\
\text { Twitter } \\
\text { Group backchannel } \\
\text { Blogs for reflections on science project } \\
\text { Making of Group Wikis on classtools.net } \\
\text { LibriVox }\end{array}$ \\
\hline Evaluation & $\begin{array}{l}\text { 1. Prepare a list of criteria to judge a singing completion. } \\
\text { 2. Critique the motives of people. } \\
\text { 3. Conduct a debate about an issue of special interest. } \\
\text { 4. Form a panel to discuss views on "Pre-Marital Sex". }\end{array}$ & \begin{tabular}{|l|} 
Digital photos \\
Digital storytelling \\
E-mail, blogs \\
Facebook \\
Flickr \\
Teaching wiki \\
Meebo Me
\end{tabular} \\
\hline
\end{tabular}

\section{Innovating Menu Blended With MI, Technology and Multimedia}

Technology has changed the face and function of modern society. The world has become technologically advanced, and classrooms are gradually following the same advancements. Moreover, today's multimedia 
which is a cautiously woven combination of text, graphic art, sound, animation and video elements are now very interactive. This makes learning more engaging, enjoyable and effective.

Zuhair (2005; as cited Fenrich, 1997) stated that multimedia is defined as the exciting combination of computer hardware and software that allows you to integrate video, animation, audio, graphics and test resources to develop effective presentations on an affordable desktop computer.

As technology becomes more inexpensive, accessible and user-friendly, teachers are also learning how technology and multimedia applications can be used as a dominant instructional tool. Commencing a constructivist learning approach, the integration of multiple intelligences, technology and multimedia is an excellent way to actively engage a student in quality learning. As such, multimedia must be outstandingly well designed.

The purpose of innovating menu blended with multiple intelligence, technology and multimedia is to explore its combined principles creating a recipe with the latest Web tools available on the net. However, it must be noted that each menu has to be hyperlinked with its specified step-by-step activity. Also, teachers need to indicate specific content to be addressed for each menu. The suggested menus that incorporate technologies to promote MI are shown in Table 3.

Table 3

Suggested Menus for MI

\begin{tabular}{|c|c|c|}
\hline MI & Multimedia/technology & Menu \\
\hline $\begin{array}{l}\text { Verbal } \\
\text { (Word smart) }\end{array}$ & $\begin{array}{l}\text { Word processors with voice annotations } \\
\text { Programs that allow children to create stories, poems } \\
\text { Word processing programs (Word) } \\
\text { Typing tutors (Mavis Beacon) }\end{array}$ & \begin{tabular}{|l} 
Blogging \\
Forums \\
Wiki compositions \\
Grazr \\
Writing new letter
\end{tabular} \\
\hline $\begin{array}{l}\text { Logical } \\
\text { (Number smart) }\end{array}$ & $\begin{array}{l}\text { Problem solving software } \\
\text { Computer aided design programs } \\
\text { Strategy game software } \\
\text { Critical thinking programs }\end{array}$ & $\begin{array}{l}\text { Linking sharer } \\
\text { Widget finding } \\
\text { Creating timeline in slide share }\end{array}$ \\
\hline $\begin{array}{l}\text { Kinesthetic } \\
\text { (Body smart) }\end{array}$ & $\begin{array}{l}\text { Software games that allow contact with the keyboard, mouse, joystick } \\
\text { Tetris game-fast decision-making + hands-eye coordination } \\
\text { Retrieved from http://www.media.mit.edu/starlogo }\end{array}$ & $\begin{array}{l}\text { Acting } \\
\text { Video clips } \\
\text { Body graphs } \\
\text { Scavenger hunt }\end{array}$ \\
\hline $\begin{array}{l}\text { Musical } \\
\text { (Music Smart) }\end{array}$ & $\begin{array}{l}\text { Videodisc player/CD-ROMs/Audio } \\
\text { Band-in-a-Box (PG software) } \\
\text { Singing software (Transforms voice input into synthesizer sounds) } \\
\text { Tone recognition and melody enhancers }\end{array}$ & $\begin{array}{l}\text { Animoto } \\
\text { LibriVox } \\
\text { Audio editing } \\
\text { Evoca/elluminate }\end{array}$ \\
\hline $\begin{array}{l}\text { Intrapersonal } \\
\text { (Self-smart) }\end{array}$ & $\begin{array}{l}\text { Career counseling software (The Perfect Career) } \\
\text { Inspiration or kidspiration } \\
\text { Intelligent Tutoring Systems (Dave ESL by MIT) }\end{array}$ & $\begin{array}{l}\text { Reporting on issues } \\
\text { Status reporting } \\
\text { Reflecting activity } \\
\text { Journal }\end{array}$ \\
\hline $\begin{array}{l}\text { Interpersonal } \\
\text { (People smart) }\end{array}$ & $\begin{array}{l}\text { MSN messenger, Net Meeting (Yahoo) } \\
\text { Electronic bulletin boards (Kidsnet) } \\
\text { Simulation games (Sim City) } \\
\text { E-mail programs (Outlook, Eudora) } \\
\text { iEARN (website) }\end{array}$ & $\begin{array}{l}\text { Forums discussions } \\
\text { Blogging } \\
\text { Vision casting } \\
\text { Chatting/email/ } \\
\text { Facebook }\end{array}$ \\
\hline $\begin{array}{l}\text { Naturalist } \\
\text { (Nature smart) }\end{array}$ & $\begin{array}{l}\text { Nature composing programs (image composer) } \\
\text { Photo paint } \\
\text { 3D software that portrays nature } \\
\text { Software games } \\
\text { Multimedia authoring programs }\end{array}$ & $\begin{array}{l}\text { Photography } \\
\text { Gcast } \\
\text { Maps } \\
\text { Research } \\
\text { Scene scout } \\
\text { Storyboarding }\end{array}$ \\
\hline
\end{tabular}




\section{Conclusions}

The growing use of e-portfolio creates the need to design a management tool to track students' e-portfolios with accuracy. This paper presents cyber portfolio as an administrative tool for monitoring students' e-portfolios. This can be a dashboard, or a blog of a class Website for linking students' e-portfolios and has specific menu functionality designed to link students' portfolios and showcase different menu blended with HOTS, MI, technology and multimedia.

Furthermore, the results of the study have shown that the construction of cyber portfolio for e-portfolios is achievable and can promote quality assessment. Later, it was also found out that it speeds up the teaching-learning process provided that students and teachers are convinced about the effectiveness of integrating cyber portfolio and e-portfolio into the course.

In view of the findings of this study, suggested samples on how to innovate a menu blended with HOTS, MI and technology were given. It is hoped that this process will not only improve cyber portfolio itself, but it will also enhance teacher-student academic exchange towards effective learning.

\section{References}

Barrett, H. (2000). Create your own electronic portfolio. Learning and Leading With Technology, 27, 14-21

Department of Instructional Technology. (1999). Portfolio examination guidelines for the master's degree University of Georgia. Retrieved 4 March, 2010 from http://it.coe.uga.edu/pdf/portguide.pdf

Gray, L. (2008). Effective practice with e-portfolios. Retrieved April 12, 2010, from http://www.jisc.ac.uk/media/documents/ publications/effectivepracticeeportfolios.pdf

Luchoomun, D., McLuckie, J., \& Wesel, M. (2010). Collaborative e-learning: E-portfolios for assessment, teaching and learning. Retrieved July 4, 2011 from www.ejel.org/issue/download.html?idArticle

Wilson, K., Crowe, M., Singh, J. ... Pyles, R. (2009). Using electronic portfolios to measure student gains from mentored research. Retrieved June 18, 2010, from http://www.cur.org/quarterly/mar09/spring09wilson.pdf

Zuhair, M. S. (2005). Development of user interface agent in multimedia courseware. Retrieved September 8, 2010, from http://www.eprints.ptar.uitm.edu.my/1580/1/MOHAMAD_SHUAIMY_BIN_OMAR_05_24.pdf 